\title{
La traducción especializada bidireccional como línea de investigación
}

\section{Bidirectional specialized translation as a line of research}

\author{
IGNACIO AHUMADA LARA \\ Consejo Superior de Investigaciones Científicas \\ ignacio.ahumada@cchs.csic.es
}

Fecha de recepción: 18 de abril de 2017

Fecha de aceptación: 15 de julio de 2017

Resumen: A pesar del título no pretendo centrarme en cuestiones de estricta factura teórica; antes bien, me ocuparé de una serie de consideraciones tanto de carácter externo como generales que me ayuden a defender y abundar en una perspectiva de investigación con escaso cultivo entre nuestros estudiosos: la investigación en traducción especializada español-otras lenguas. Cuando me refiero a la investigación en traducción especializada bidireccional, lo hago con referencias exclusivas a la modalidad de traducción escrita, lo que no supone que la propuesta no sea ampliable a otras diferentes modalidades o variantes.

Con la llegada de los estudios de Traducción a la universidad española, hace ahora tres décadas, las diferentes líneas de investigación traductológica han dirigido su atención de forma casi unánime hacia el estudio del español como lengua meta; en realidad, asumíamos en buena medida una tradición multisecular.

La traducción especializada bidireccional plantea el estudio del español, y en consecuencia de la recepción de la ciencia, desde una doble perspectiva: el español como lengua de llegada (meta) y el español como lengua de partida (fuente). Los principios y métodos de análisis -como es evidente- pudieran ser comunes o cuasi comunes a ambas direcciones: la esencial tetraclasificación del método traductor, el análisis lingüístico, el estilístico, el cultural, la invariación, la adecuación, la equivalencia, etc. La diferencia fundamental estriba en el análisis lingüístico, estilístico y cultural del doble proceso al que se somete una misma lengua, que bien pudiera dar lugar a esclarecedores estudios comparativos.

Palabras clave: Lingüística, lengua española, traducción especializada otras lenguas-español, traducción especializada español-otras lenguas. 
Abstract: Regardless of the title I do not pretend to focus my attention in questions of strict theoretical account rather I will occupy myself by a series of considerations not only in external terms but also in general ones which aid me to defend and abound in a perspective of investigation with scarce cultivation among our scholars: the investigation in specialised translation Spanish-other languages. When I am referring to investigation in bidirectional specialised translation, I point to exclusive references to written translation modality, what do not suppose that the proposal cannot be expanded to different modalities or variations.

With the arrival of Translation Studies in the Spanish university system, three decades ago, the different lines of investigation in translation have attracted their attention in an almost unanimous manner towards the study of Spanish as target language; as a matter of fact, we assumed in good measure a multi secular tradition.

Bidirectional specialised translation poses the study of Spanish, and as a consequence, of the reception by science, from a double perspective: Spanish as a target language and Spanish as a source language. The principles and methods of analysis, as it is evident, could be common or quasi-common in both directions: the essential tetra classification of the translation method, linguistic analysis, stylistic or cultural ones, invariance, adequacy, equivalence, etc. The fundamental difference consists of the linguistic, stylistic and cultural analysis of the double process to which a language is submitted. Thus, it could be the cause of illuminating comparative studies.

Key words: Linguistics, Spanish language, specialized translation from any language into Spanish, specialized translation from Spanish into other languages.

\section{INTRODUCCIÓN}

En Traducción se plantea como punto de partida clasificatorio una tipología organizada en tres grandes áreas, cuyo reconocimiento general admite como áreas convencionales: (1) traducción general, (2) traducción literaria y (3) traducción especializada. Es evidente que, tanto en el plano teórico como en el plano práctico de la Traducción, esta tripartición nos viene avalada, amén de por la tradición (factores externos), por los rasgos distintivos y definitorios de cada una de esas tres grandes áreas.

En Lingüística (y las lenguas fuente y meta constituyen la piedra angular que desecharon los arquitectos) se distingue entre lengua general y lengua especializada. Si situáramos ambas en el mismo nivel categorial, como aquel otro de lengua (traducción) y habla (interpretación), bien pudiera 
valer la oposición para reducir a dos las consabidas tres áreas convencionales. Distinguiríamos, pues, entre (1) traducción general y (2) traducción especializada. En consecuencia, toda aquella traducción escrita que no correspondiera a la distribución multidisciplinar que recoge, por ejemplo, la clasificación UNESCO para las ciencias, debería entenderse como traducción general, incluida — con todos mis respetos-, la traducción literaria. ${ }^{1}$

Hoy, por ejemplo, a partir de la técnica empleada, se habla de traducción automática, de traducción semiautomática y, en última instancia, de memorias de traducción.

En cualquier clasificación, si aplicamos con rigurosidad el principio rector, tan válido puede resultar como criterio (1) la tradición, (2) el estrictamente lingüístico y (3) el recurso técnico del que nos auxiliamos a la hora de traducir cualquier texto hablado o escrito. ${ }^{2}$

Sin lugar a dudas, ya se trate de traducción general ya se trate de traducción especializada, la capacidad, la intuición, el dominio de ambas lenguas, la destreza técnica... del traductor son requisitos imprescindibles que coadyuvan al resultado satisfactorio tanto para propios como para extraños.

\section{BIDIRECCIONALIDAD: PERSPECTIVA HISTÓRICA}

A lo largo del siglo XVI la difusión de la literatura española en Europa discurre tanto por el camino de la lengua vernácula ${ }^{3}$ como por vía de la traducción a las diferentes lenguas modernas del continente: «Traducidos a varios idiomas, el Amadís, la Cárcel de amor y la Celestina inauguraron los triunfos de nuestras letras en el extranjero» (Lapesa, 1980: 292/§ 74, 2). ${ }^{4}$ En años posteriores el Lazarillo y la Diana de Montemayor, Luis de Granada, Teresa de Jesús, Juan de la Cruz, Cervantes, Lope, Calderón, etc. (Íd., ib.). El teatro español logra en la escena europea un reconocimiento sin precedentes a través de traducciones directas, indirectas a través del francés (o del italiano) o bien por medio de reelaboraciones de la obra original española:

\footnotetext{
${ }^{1}$ Otrora, la traducción literaria se ha visto en pie de igualdad frente a la traducción general.

2 Para el complejo entramado clasificatorio sobre la traducción y su tipología, así como los diferentes métodos, clases, tipos, modalidades, etc. puede consultarse Albir, 2004: 43-95.

${ }^{3}$ No solo para lectores españoles de la Europa renacentista, por ejemplo, sino también para los hablantes nativos franceses, italianos o flamencos. Es notoria, por ejemplo, la edición de textos en español en ciudades como Roma, Venecia, Nápoles o Sicilia. Baste señalar la labor editorial en Venecia del clérigo andaluz Francisco Delicado en obras como la Celestina (1531 y 1534), el Amadís (1533) o los tres libros del Primaleón et Polendos (1534) (cf. Ahumada, 2009: 22-25).

${ }^{4}$ En cambio, la primera traducción al inglés de una lengua iberorromance ocurre en 1484: The book of the chyvalry correspondiente a El libre del Orde de Cavayleria, de Ramón Llull (1275) (cf. Pane, 1944: v).
} 
Un claro ejemplo [del éxito de Calderón en Holanda] es La vida es sueño, convertida en Segismundus, Prince van Polen, estrenada en 1654 y representada sin interrupción hasta 1658, convirtiéndose así en la pieza más exitosa del teatro español en Holanda (Braga, 2009: 44).

A diferencia del texto literario el texto especializado es menos susceptible de reelaboración por parte del traductor, pero como texto fuente se traslada - como veremos de inmediato-, ya en el siglo XVI, a cualquier lengua moderna, además del latín. La invariación, al tratarse de un texto científico debería ser, stricto sensu, el principio rector. Como en cualquiera otro texto fuente la necesidad marcada por el receptor determinan, de manera general, las adiciones, supresiones, adecuaciones, entre otras, en la lengua meta (cf. Ahumada, 2016).

\subsection{Dirección otras lenguas-español}

En el seno de la Biblioteca Virtual Miguel de Cervantes se aloja una de las herramientas de mayor utilidad para los estudios de Traducción desde la perspectiva histórica: la Biblioteca de Traducciones Españolas. El portal está dirigido por los profesores Francisco Lafarga y Luis Pegenaute, quienes, en su ya larga y fructífera trayectoria investigadora, culminan una etapa más ofreciendo a la comunidad científica datos de un valor incalculable para el futuro desarrollo de la investigación en Traducción. ${ }^{5}$

Para la ocasión he revisado la bibliografía general firmada por Francisco Lafarga (Lafarga, 2017), cuyo cierre cronológico se produjo hace apenas seis meses (15/05/2017). Desde el punto de vista geográfico -imprescindible para mis apreciaciones-, la producción bibliográfica registrada sobre la traducción se concreta al ámbito peninsular. ${ }^{6}$ Del destacado volumen de información aportado he extraído aquellas referencias

${ }^{5}$ Mucho me temo, a tenor de las palabras del profesor Lafarga («Un trabajo de estas características, como es obvio, puede padecer errores y ausencias»), que la crítica fácil reseñe la falta de determinadas referencias. He de decir, sin embargo, que nadie que no haya redactado jamás un diccionario -ya sea de lengua, especializado o bibliográfico- podrá reconocer suficientemente la ingente labor de recopilación léxica, especializada o bibliográfica llevada a cabo por los equipos que se ocupan de estas tareas. Las exigencias de determinados investigadores, cuyos trabajos son meramente descriptivos de los materiales que reúnen los diccionarios, evidencian la distante relación que mantienen tanto con la ardua tarea que supone la redacción de diccionarios como las limitaciones impuestas por la propia naturaleza de las obras sobre las que se trabaja. Centrándonos de nuevo en las recopilaciones bibliográficas: entiendo que su conocimiento y estudio (el estado de la cuestión en cinco palabras) continúa siendo el punto de partida imprescindible para toda investigación que se precie: el puro descriptivismo sin los precedentes, cuando los hubiera, rebaja el valor necesario de las posibles aportaciones para la contextualización del fenómeno estudiado (v. Ahumada, 2017b).

${ }^{6} \mathrm{Y}$ en cuanto tal, se incorporan referencias tanto para el vascuence como para las lenguas iberromances del catalán y del gallego.

Hikma 16 (2017), 59-72 
que entiendo podríamos clasificar, sin temor a equivocarnos, como traducción especializada (sentido laxo). Si el número total de entradas asciende a algo más de siete mil referencias entre generalidades, biobibliografías de autores/traductores y trabajos específicos sobre las lenguas española, vascuence, catalán y gallego, el número de referencias sobre traducción especializada en lengua española asciende a algo más de trescientas. La mayor parte, en consecuencia, corresponde a trabajos relacionados, mutatis mutandis, con la traducción literaria.

El recuento llevado a cabo arroja los siguientes resultados: Filosofía y Ensayo supera con creces a cualquiera otra disciplina (72 referencias), le siguen, Economía (20), Historia natural (18), Medicina (17) y Química (14). Dejamos de reseñar los puestos intermedios. Los últimos lugares los ocupan los trabajos relacionados con el Derecho (2), la Educación (2), la Lingüística (2), la Música (2), las Matemáticas (1) y la Geografía (1).

La elevada cifra de trabajos sobre las lenguas especializadas relacionados con la Filosofía y el Ensayo nos la confirma el número de obras digitalizadas en lo que se denomina en la plataforma como "Contenidos esenciales": al lado del extenso repertorio sobre traducciones literarias figuran traducciones sobre obras de Aristóteles, Boecio, Darwin, Kant, Lamennais, Muratori, Prescott y Rousseau. Fuera de este ámbito: Los diez libros de arquitectura de Vitruvio. ${ }^{7}$

\subsection{Dirección español-otras lenguas}

Apenas si pueden contarse con los dedos de la mano los trabajos de investigación desarrollados en la dirección contraria a la que acabamos de revisar (cf. Ahumada, 2017a). Este fue el motivo que llevó a plantearnos en el grupo de investigación ELCI (El español, lengua de la ciencia) el estudio de las traducciones especializadas a partir del español como lengua fuente.

Pesaba sobre nuestra lengua de la ciencia la desafortunada sentencia unamuniana «iQué inventen ellos!», aunque ya en la Restauración y en los albores de la Edad de Plata contábamos con contribuciones como la de Marcelino Menéndez Pelayo ([1876]/1973-1974) o la de Felipe Picatoste (1891), entre otras.

El proyecto sobre la recepción de la ciencia española en Europa a través de la traducción especializada, cuyos inicios arrancan en 2012, pretende inventariar, describir y estudiar históricamente el impacto de las obras de las ciencias experimentales, de la tecnología, de las ciencias sociales y de las ciencias humanas, pilares de la clasificación de la Ciencia, escritas en español y traducidas a las diferentes lenguas modernas de

7 En la Bibliografía de estudios sobre historia de la traducción en Hispanoamérica (Lafarga/Pegenaute, 2017), los trabajos sobre las lenguas de especialidad en el español de América presentan índices mucho más bajos. 
Europa. Partimos del supuesto según el cual el traslado de una obra científica a otra lengua es muestra más que suficiente del interés de la comunidad científica general por las aportaciones individuales o colectivas de los científicos de un país determinado y en una lengua determinada.

Los documentos objeto de estudio están sujetos a la clasificación UNESCO de las ciencias en solo sus dos primeros apartados: áreas y campos.

Clasificación por áreas: I. Ciencias exactas y Ciencias naturales, II. Ingeniería y Tecnología, III. Ciencias médicas, IV. Ciencias agrarias, V. Ciencias sociales, VI. Humanidades. ${ }^{8}$

Clasificación por campos: 11. Lógica; 12. Matemáticas; 21. Astronomía y Astrofísica; 22. Física; 23. Química; 24. Ciencias de la vida; 25. Ciencias de la Tierra y del Espacio; 31. Ciencias agrarias. 32. Ciencias médicas. 33. Ciencias tecnológicas. 51. Antropología. 52. Demografía; 53. Ciencias económicas; 54. Geografía. 55; Historia. 56; Ciencias jurídicas y Derecho; 57. Lingüística; 58. Pedagogía; 59. Ciencia política; 61. Psicología; 62 Ciencias de las artes y las letras; 63 . Sociología; 71 . Ética y 72. Filosofía.

Al situarnos en el terreno de la Lingüística y de la Traduccción, y en concreto de la lengua española y de las diferentes lenguas modernas de Europa, la cronología de la investigación se centra fundamentalmente en las obras científicas escritas en español y traducidas a las diferentes lenguas de Europa entre los albores del siglo XVI y el año de 1945. Entendemos, pues, el año 1945 como el punto de partida decisivo para la entronización de la lengua inglesa como lengua de la ciencia. ${ }^{9}$

El proyecto se ha diseñado dentro de la dimensión panhispánica del español. Veamos algunos ejemplos.

Durante el siglo XVI algunos de los tratados de Náutica escritos en español (Pedro de Medina o Martín Cortés) tuvieron traslado a lenguas como el alemán, inglés, italiano o francés. En Ciencias médicas, Valverde de Hamusco, Monardes y Acosta. Alonso de Herrera representa con su Agricultura a las Ciencias agrarias. Nada de esto fue comparable, puesto que nos encontramos en el germen de nuestra leyenda negra, a la Breuísima relación de la destruyción de las Indias colegida por el obispo don fray Bartolomé de las Casas (holandés, francés, inglés, alemán y latín). Frente a Las Casas debemos situar a Díaz del Castillo o Núñez Cabeza de Vaca, conquistadores, que defendían la postura contraria y que también contaban con sus seguidores en Europa.

\footnotetext{
${ }^{8}$ En las consideraciones que siguen en esta muestra solo trabajaremos con las seis grandes áreas de clasificación.

${ }^{9}$ Carlos Alvar cuenta con varios trabajos sobre la traducción especializada en el período medieval, tanto en la dirección otras lenguas-español (profusamente) como español-otras lenguas (Alvar, 2010).
} 
En el siglo XVII el peso de Trento se dejó notar en el desarrollo científico. América, sin embargo, seguía despertando el interés de los europeos: Antonio Colmenero de Ledesma, Cvrioso tratado de la natvraleza y calidad del chocolate (1631) y Álvaro Alonso Barba, Arte de los metales (1640) mantuvieron el interés por la Tecnología que se desarrollaba en la América española.

La llustración nos proporciona nombres tan relevantes en el campo de la Historia natural como Guillermo Bowles. En las Ciencias médicas contamos con dos nombres vinculados estrechamente al estudio de productos americanos: Francisco Xavier Balmis (ágave y begonia) e Hipólito Ruiz López (ratania). Sin olvidarnos del mismísimo «rev. father Feyjoo» y sus tres discursos sobre la Medicina. ${ }^{10}$ En el campo de las Ciencias sociales figura Jerónimo de Ustáriz con la Theórica y práctica del comercio y la marina (1742). ${ }^{11}$

En el siglo XIX español las aportaciones de nuestros científicos aumentan y con ello el número de traducciones a las lenguas modernas de Europa. Destacan los tratados de Simón de Rojas Clemente y Rubio en Ampelología (Ciencias Naturales), los médicos andaluces Pedro M. a González y José Manuel de Aréjula, en Ciencias sociales la obra de Jordán de Asso y Mariano Torrente, y, por último, en el área de Humanidades: Jaime Balmes y Ceferino González (Filosofía), José Antonio Conde, Manuel José Quintana y Adolfo de Castro (Historia), entre otros.

Parejamente asistimos a la decisión por parte de nuestros científicos de escribir su obra directamente bien en francés (Félix de Azara, Domingo Badía, José M. a Lanz/Agustín de Betancourt, Carlos de Gimbernart, Manuel Hurtado de Mendoza, Juan Bautista Arrambide, etc.), a la sazón la lengua de la ciencia; bien lo hacen en alemán (Fausto de Elhuyar). ${ }^{12}$

La dimensión panhispánica del proyecto nos ofrece nombres como Francisco Xavier de Gamboa (1761), Joseph Felipe Flores (1782) y Carlos Juan Finley y Barrés (1881-1882), cuyas aportaciones fueron traducidas al inglés.

La ciencia española con proyección internacional conocería aún una etapa de auge sin precedentes: la Ilamada Edad de Plata, integrada por figuras tan relevantes en el plano exterior como Isaac Peral, Leonardo Torres Quevedo, Blas Cabrera o Santiago Ramón y Cajal, entre otros.

\footnotetext{
${ }^{10}$ La leyenda negra sobre España vuelve a pesar en las palabras del anónimo traductor, quien se extraña de que un tratado de física (medicina) lo haya escrito un español y, todavía más, que se trate de un fraile: Rules for preserving health particularly with regard to studious persons in three treatises translated from Spanish (1787).

11 The theory and practice of commerce and maritime affairs [...] translated from the original by John Kippax, Dublín, 1752.

12 Un avance de las traducciones indirectas alemanas a través del francés puede consultarse en Ahumada/Jelovac, 2015.
} 
De Santiago Ramón y Cajal, cuyas primeras traducciones al alemán arrancan en 1899, es de sobra conocido el éxito editorial a nivel mundial de su obra: Reglas y consejos sobre la investigación científicas. Los tónicos de la voluntad (Madrid, 1897/1923). A partir de la sexta edición española (1923) se tradujo al húngaro (1927 y 1930), al alemán (1933, 1938, 1939, 1957 y 1963) (cf. Jelovac, 2014: en prensa), al japonés (1958, 1980 y 1981), al portugués (1942 y 1979), al inglés (1951 y 1999), al rumano (1967 y al serbio (2007).

\section{UNA MUESTRA}

Mantenemos de nuevo el par traducción literaria/traducción especializada. Va a ser la traducción literaria aquella que nos proporcione los dos primeros ejemplos sobre las posibilidades de estudio (formal, estilístico, cultural, etc.) de la línea bidireccional español-otras lenguas.

\section{1. iCiertos son los toros!}

El estudio de las traducciones especializadas español-otras lenguas por traductores nativos ayudaría con toda probabilidad a mejorar notablemente nuestros conocimientos sobre el español como lengua de partida, así como las dificultades que entraña - aunque se trate de lenguas especializadas- su traslado a otras lenguas. De nuevo los ejemplos nos llegan de la mano de la traducción literaria, a todas luces reconocida como una línea de investigación preferente.

Sea la locución española ;ciertos son los toros! Aparece registrada en el Quijote en boca de Sancho:

- ¿No lo dije yo? -dijo oyendo esto Sancho-. Sí que no estaba yo borracho: ¡mirad si tiene ya puesto en sal mi amo al gigante! ¡Ciertos son los toros: mi condado está de molde! (Cervantes, Quij., I, XXXV).

Joaquín Segura - de quien tomamos la muestra- ha elogiado recientemente la impecable traducción inglesa de Don Quijote llevada a cabo Edith Grossman en 2003. ${ }^{13}$ Para Grossmann, ${ }^{14}$ quien ha trasladado el texto cervantino al inglés contemporáneo, la locución jciertos son los toros! ha sido traducida como now is for sure! Al decir de Segura, la versión de Grossmann frente a la de otros traductores supone un paso de gigante. Es más, la traductora incluye una nota a pie de página en la que recoge a modo de ejemplo la solución propuesta por otros colegas:

${ }^{13}$ Debe tenerse presente que Joaquín Segura ha dedicado gran parte de su trayectoria profesional a la traducción especializada.

${ }_{14}$ Miguel de Cervantes, Don Quixote, a new translation by Edith Grossman, introduction by Harold Bloom, New York, Ecco-Harper Collins Publishers, 2003. 
Putnam [1949] traduce esta última expresión como: You can depend on the bulls y en la segunda nota al pie explica cómo la tradujeron algunos predecesores: Ormsby has There is no doubt about the bulls, and explains the saying as expressive probably of popular anxiety on the eve of a bull-fight. Motteux and Jarvis have: Here are the bulls; Lockhart's expression being in allusion to the joy of the mob in Spain when they see the bulls running (Segura, 2008: 962-963).

El ejemplo aducido tiene además un valor añadido, que voy a permitirme comentar.

La locución iciertos son los toros! se documenta -como apunta Segura en su trabajo- en los diccionarios académicos de más reciente datación, esto es, con plena vigencia cuando se realizaron las traducciones mencionadas de Putnam, etc. Pues bien, la locución se encuentra ya en Autoridades (1739) avalada por una cita del Diálogo de los médicos (1547) del sevillano Pedro Mexía: «Aun podría ser que fuesen ciertos los toros, señor Maestro, si el señor Bernardo tiene gana».

Sebastián de Covarrubias, afanado siempre en ahondar en la naturaleza misma de las palabras (etimología), incluso apunta hasta su posible justificación a partir de la realidad:

ciertos son los toros frasis ordinaria, quando la cosa de que dudamos da indicios de ser cierta, como quando los toros están ya encerrados en el toril de la plaça (Covarrubias, 1611: s. v. toro).

Desde esta primera datación lexicográfica (1611) hasta la más reciente en el diccionario académico (2014):

ciertos son los toros expr. coloq. Ú. para afirmar la certeza de algo, por lo general desagradable, que se temía o se había anunciado (DRAE, 2014: s. v. toro).

La locución que nos ocupa no ha dejado de ocupar un lugar preferente en la microestructura de los principales diccionarios del español. ${ }^{15}$

\footnotetext{
${ }^{15}$ La enseñanza del español en los Estados Unidos generó una serie de materiales didácticos de elevada calidad tipográfica y filológica. Me refiero a las diferentes ediciones de obras clásicas y contemporáneas acompañadas de introducción, notas, ejercicios y vocabulario nacidas al amparo de las universidades de Harvard, Yale, Columbia o Nueva York y de nombres tan prestigiosos como George Ticknor, principalísimo impulsor, Henry Wadsworth Longfellow, James Russell Lowell, Washington Irving y William Prescott. Creo oportuno recordar en este sentido las palabras de Ofelia García sobre los orígenes de la enseñanza del español como lengua extranjera en los Estados Unidos: «El objetivo de esa enseñanza universitaria no era la adquisición del español, y por ende el bilingüismo, sino la interpretación de textos literarios y el desarrollo de conocimientos filológicos» (García, 2009: 423).
}

Hikma 16 (2017), 59-72 
El valor añadido a la muestra que acabo de exponer le viene otorgado por las reticencias que suelen mantener los traductores hacia los diferentes repertorios lexicográficos, así monolingües, como bilingües o plurilingües: «La méfiance à l'égard du dictionnaire est beaucoup plus répandue qu'on ne le croit généralemen» (Maillot, 1969: 124).

\subsection{Platero, Platerón, Platerillo, Plateriiillo, Platerete, Platerucho...}

La siguiente muestra podríamos adscribirla tanto al estudio de los rasgos formales (variantes del diminutivo) como al estudio de los llamados elementos culturales (variantes dialectales).

El empleo del diminutivo en las hablas meridionales del español, especialmente Andalucía y Canarias, no tiene comparación estadística con su uso en las hablas septentrionales. Si la proporción la establecemos entre las variedades meridionales y las variedades del español de América, estas últimas sobrepasarían cualquier límite establecido.

Martín B. Fischer comparó dos ediciones alemanas de Platero y yo anteriores a la concesión del Nobel a Juan Ramón Jiménez en 1956. ${ }^{16}$ Si la obra en sí misma es de una complejidad extrema para el lector nativo, cuanto menos no lo es para un traductor, que, por añadidura, ha de trasladarlo a una lengua como la alemana. La aparente sencillez estilística y uso de un léxico general encierran, sin duda, una de las obras más atractivas de nuestra literatura para la crítica más avezada. ${ }^{17}$

Me voy a permitir entresacar dos citas (análisis estilístico y factores culturales) del trabajo de Fischer para ilustrar este apartado:

Vistas las dificultades, sobre todo de tipo gráfico y fonético, de agregar los diminutivos alemanes (-chen y -lein) a un nombre propio extranjero Vogelgsang deja los apodos de Platero sin traducir. Cuando se trata del nombre genérico sí traduce. La traducción de Deinhard demuestra que, aun recurriendo a la duplicación de diminutivos, las posibilidades del

Sobre este tema, durante el pasado curso, se ha defendido en la Universidad de Sevilla la tesis doctoral de Iván A. Sanchiz Pedregosa, La literatura española en la enseñanza del español como segunda lengua en los Estados Unidos (1890-1939), Sevilla, 2017.

16 Platero y yo, más allá de la crítica literaria, suele aparecer adscrito al subgénero de la literatura infantil. Nada más lejos de la realidad.

${ }^{17}$ Salvando las distancias, recuerdo la complejidad que encerraba el ejercicio que debían llevar a cabo los estudiantes del Máster universitario en traducción especializada (inglés/francés/alemán-español), de la Universidad de Córdoba, en el módulo «Fundamentos y técnicas de la investigación en Humanidades", bajo mi tutela. La parte práctica del módulo consistía en el «Estudio comparativo de los recursos traductológicos (inglés/francés/alemán) del habla popular en textos literarios españoles». El texto literario a la sazón no era otro que el Retrato de la loçana andaluza (1530). A las dificultades intrínsecas de la variante dialectal andaluza se sumaba el español estándar del siglo XVI. Esto ocurría en el curso 2010-2011.

Hikma 16 (2017), 59-72 
alemán a la hora de encontrar equivalencias para la riqueza morfológica del castellano son limitadas (Fischer, 2001: 32).

Un problema para los traductores son las transcripciones de diálogos en dialecto. Deinhard opta por la traducción en registro estándar mientras Vogelgsang se decide por rasgos dialectales del sur de Alemania. Este procedimiento de traducir una variante regional por otra de la lengua de llegada es muy discutida entre los estudiosos ya que da la impresión de trasladar geográficamente el lugar de acción y correr el peligro de resultar cómico sin querer (Fischer, 2001: 34) (v. Mayoral, 1990).

\subsection{Traducción especializada: Ciencias naturales y médicas}

Como señalo más arriba, las posibilidades de análisis que nos proporciona la traducción especializada bidireccional corre por similares derroteros en ambas direcciones. De los primeros resultados que los integrantes del grupo hemos adelantado en diferentes reuniones científica voy a señalar, para la ocasión, un caso de corrección de erratas del original francés que sirve de base a la traducción indirecta del alemán. La obra de base no es otra que Ensayo sobre las variedades de la vid común que vegetan en Andalucía (1807) del naturalista valenciano Simón de Rojas Clemente y Rubio:

El traductor alemán modifica el nombre de la cepa que se utiliza tanto en la versión original como en la traducción francesa: Crus gracilis y crus crassus. Ambas expresiones se modifican en crus gracile y crus crassum, para lograr así una concordancia de género adecuada al uso del latín clásico (Jelovac/Jacinto, 2017: en prensa).

En cambio, se produce un error en la transmisión de varios verbos usados en una extensión geográfica reducida:

"Estas dos propiedades de echar agracejo y uva menuda se expresan en el Reyno de Granada con el verbo alherear o alhelear, y en Castilla con los de lardear, ardalear y ralear" (Clemente, 1807).

"Diese zwei Eigenschaften einer Traube, Grest und Klein-Beere, so wie sehr entfernstehenden Beeren zu geben, werden im Königreiche Granada durch das Wort adherear [sic], und in Kastilien durch lardear (das heisst: dass sich die Trauben lichten) ausgedruckt“ (Clemente, 1821) (Jelovac/Jacinto, 2017: en prensa).

Por lo que hace a la adecuación del texto original a los potenciales lectores, ejemplifico con la obra científica en español con mayor repercusión mundial: Reglas y consejos sobre la investigación científicas. Los tónicos de la voluntad (Madrid, 1897/1923). 
En las ediciones alemanas (1933, 1938, 1939, 1957 y 1963), que además sirvieron de base a las tres ediciones japonesas (1958, 1980 y 1981), fueron suprimidos los capítulos correspondientes a la situación de la investigación en España y la política para el fomento de la misma (cf. Jelovac, 2014: en prensa).

\section{CONCLUSIÓN}

En consecuencia, en el proyecto La recepción de la ciencia española en Europa a través de la traducción especializada trabajamos a partir de estas dos hipótesis:

(1) Si el impacto de una publicación científica fuera de nuestras fronteras es el referente de la internacionalización de la ciencia española en la sociedad actual, la traducción de las obras científicas españolas a las distintas lenguas modernas de Europa puede ayudar, con toda probabilidad, a determinar ese impacto internacional.

(2) Un segundo índice para medir ese impacto internacional sería la incidencia real de esas traducciones en la producción científica del país o de los países que han demandado la traducción, lo que nos lleva estudiar como el aspecto decisivo del funcionamiento de texto en la comunidad científica receptora (cf. Toury, 1997: 71).

En definitiva, la investigación en traducción especializada bidereccional nos permitiría lograr con su práctica ese difícil equilibrio entre el conocimiento y el dominio que todo traductor se autoexige sobre las dos lenguas en juego.

\section{REFERENCIAS BIBLIOGRÁFICAS}

AHUMADA, Ignacio, "Edición bilingüe y estudio preliminar". En: Delicado, Francisco, El modo de usar el palo de India occidental, saludable remedio contra toda llaga y mal incurable. Jaén: Universidad de Jaén, 2009, pp. 1-94.

- " "Invariación y adecuación en teoría de la traducción: metalexicografía en el Dictionnaire de la conversatión et de la lecture (1835) y en la Enciclopedia moderna (1852)". En: Bulletin Hispanique, 118/1, 2016, pp. 305-318.

-, "La recepción de la ciencia española en Europa: la traducción especializada bidireccional". En: VI Reunión internacional de la Red temática Lengua y Ciencia. Madrid, 22 al 24 de febrero de 2017 (en prensa), 2017a.

-, (dir./ed.). Bases de datos Nebrija-Valdés: Diccionario bibliográfico de la metalexicografía del español (DBME) (Orígenes-año 2010). 2017b. Disponible en línea en:

<http://www.investigacion.cchs.csic.es/elci/node/10> [Fecha de consulta: 20/10/2017] 
- y Jelovac, A., "Notas sobre la recepción de la ciencia española en lengua alemana a través de las ediciones en lengua francesa (1787-1829)". En: Checa Beltrán, José (ed), La cultura española en la Europa romántica. Madrid: Visor, 2015, pp. 189-208.

Alvar, Carlos, "Alfonso $x$ traducido al francés en la Edad Media. Algunos textos". En: Traducciones y traductores. Materiales para una historia de la traducción en Castilla durante la Edad Media. Alcalá de Henares: Centro de Estudios Cervantinos, 2010, pp. 431-445.

Braga RierA, Jorge, La traducción al inglés de las comedias del Siglo de Oro. Madrid: Editorial Fundamentos, 2009.

CovarRUBIAS, Sebastián de, Tesoro de la lengua castellana o española. Madrid: Luis Sánchez, impresor, 1611.

FISCHER, Martin B. "Platero y yo en alemán". En: Pegenaute, Luis (ed.), La traducción en la Edad de Plata. Barcelona: Promociones y Publicaciones Universitarias S. A., 2001, pp. 27-40.

GARCíA, Ofelia, "La enseñanza del español como lengua extranjera". En: López Morales, Humberto (coord.), Enciclopedia del español en los Estados Unidos. Anuario del Instituto Cervantes, 2008, Madrid, Instituto Cervantes-Santillana, 2009, pp. 423-428.

HURTADO AlBIR, Amparo. Traducción y traductología. Introducción a la traductología, 2. ${ }^{a}$ ed. Madrid: Cátedra, 2004.

JeLOVAC, Amila, "La recepción de la obra de Ramón y Cajal y su traducción en Alemania: Reglas y consejos sobre investigación científica. Los tónicos de la voluntad/Regeln und Rastchläge zur wissenchaftlichen Forschung (1933)". En: XI Congreso Internacional de Traducción, Texto e Interferencias. Universidad de Internacional de AndalucíaBaeza, 2014 (en prensa).

- y JACINTO, Eduardo "La ciencia española decimonónica y su recepción en Alemania y Austria: la traducción del Ensayo sobre las variedades de la vid común que vegetan en Andalucía (1807) de Simón de Rojas". En: VI Reunión internacional de la Red temática Lengua y Ciencia. Madrid, 22 al 24 de febrero de 2017 (en prensa).

LAFARGA, Francisco, Bibliografía de estudios sobre historia de la traducción en España. 2017. Disponible en línea en:

<http://www.cervantesvirtual.com/portales/biblioteca_traducciones_es panolas/documentacion_bibliografia/> [Fecha de consulta: 02/10/2017]

- y PEGENAUTE, Luis, Bibliografía de estudios sobre historia de la traducción en Hispanoamérica. 2017. Disponible en:

<http://www.cervantesvirtual.com/portales/traducciones_hispanoameri canas/bibliografia/> [Fecha de consulta: 07/10/2017].

LAPESA, Rafael, Historia de la lengua española, 8. ${ }^{a}$ ed. Madrid: Editorial Gredos, 1980. 
MAILLOT, Jean, La traduction scientifique et technique. Paris: Éditions Eyrolles, 1969.

MenÉNDEZ Pelayo, Marcelino, La ciencia española. Santander: Consejo Superior de Investigaciones Científicas, 3 vv. [1876] 1973-1974.

PicATOSte y RODRíGueZ, Felipe, Apuntes para una biblioteca científica española del siglo XVI. Madrid: Imp. M. Tello, 1981.

Real Academia Española, Diccionario de la lengua española, 23. ${ }^{a}$ ed., Barcelona, Espasa Libros.

SEGURA, Joaquín, "Traducción y traductores". En: López Morales, Humberto (coord.), Enciclopedia del español en los Estados Unidos. Anuario del Instituto Cervantes, 2008, Madrid, Instituto Cervantes-Santillana, 2009, pp. 961-972.

TOURY, Gedeon, "What lies beyond descriptive translation studies?". En: Vega, Miguel Ángel/Martín-Gaitero, Rafael (ed.), La palabra vertida. Investigaciones en torno a la Traducción. Actas de los VI Encuentros en torno a la Traducción. Madrid, Editorial Complutense-Instituto Universitario de lenguas Modernas y Traductores, 1997. pp. 69-80. 